\title{
EVALUATION ON URBAN LAND EXPANSION QUALITY OF QINGDAO CITY FROM 2010 TO 2018
}

\author{
T Zhang ${ }^{1}$, H. Dai ${ }^{1,2}$, G. Wang ${ }^{1,3 *}$, L. Zheng ${ }^{1}$, M. Zhang ${ }^{1,2}$ \\ 1 Land Satellite Remote Sensing Application Center, Ministry of Natural Resources of P. R. China, - (zhangt, wanggh, \\ zhenglj)@lasac.cn \\ 2 Beijing Satlmage Information Technology Co. Ltd., Beijing, 100048, P. R. China, -(daihl, zhangm)@ satimage.cn \\ 3 School of Environment and Spatial Informatics, China University of Mining and Technology, Xuzhou 221116, P. R. China
}

KEY WORDS: Urban land expansion, spatiotemporal pattern, Qingdao city.

\begin{abstract}
With the process of people moving from rural to urban area, the urban land boundary expanded significantly. In this paper, the urban land areas of Qingdao were extracted by using remote sensing images from 2010 to 2018. The spatiotemporal pattern of urban expansion in Qingdao city was revealed. Furthermore, the land cover type of the urban expansion area and urbanization rate were also analyzed to study the quality of urban expansion in different counties. It has shown that over $95 \%$ land cover types are impervious in the build-up areas of Qingdao, e.g. Shibei and Shinan district. However, there are more forest and water land exist in the suburban counties. The urban land expansion rate and people urbanization rate are highly related.
\end{abstract}

\section{INTRODUCTION}

Urban land is an important living space for human being. With the growth of population and increase of wealth, more and more people move from rural to urban area. Therefore, the urban land expands significantly. Revealing the spatiotemporal pattern of urban expansion is with great meaningful for making decision to optimize land use patterns, and to promote the effective development of cities.

Remote sensing is an ideal way to monitor the urban land expansion because the results obtained from remote sensing image are objective. Previous research has shown the land expansion pattern of different cities in China based on optical remote sensing images and night time light data (Chai and $\mathrm{Li}$, 2018; Wang et al., 2019; Yu et al. 2021; Li and Li, 2015). However, most researches focus on urban boundary extraction, urban land expansions, revealing the spatiotemporal pattern (Gao et al., 2012; Wang et al., 2012). However, the quality of urban land expansion, including the land cover types in the built-up area, as well as the coordination between urban land expansion and population growth, were rarely mentioned.

Qingdao city is located in eastern Shandong Province on the east coast of China, which developed very fast over the last decades. In this paper, taking Qingdao city as the study area, the high-resolution remote sensing images were used to extract urban boundaries from 2010 to 2018. Furthermore, the land cover type of the urban expansion area and urbanization rate were also analyzed to study the quality of Qingdao urban expansion.

\section{STUDY AREA}

Qingdao is located on the southeast coast of Shandong Peninsula, and it is an important city in Shandong Province on the east coast of China. It is a megacity specifically designated in the state plan, a sub-provincial city, and the economic center of Shandong Province. Qingdao city administers 7 districts and 3 county-level cities, i.e, Shibei, Shinan, Licang, Huangdao, Chengyang, Laoshan, Jimo, Jiaozhou, Pingdu, and Laixi. Most of the areas in Qingdao city have an elevation less than 100 meters, and the mean elevation is 56.5 meters (Figure 1). Pingdu, Laoshan, and Huangdao have higher elevation comparing with other districts and county-level cities.

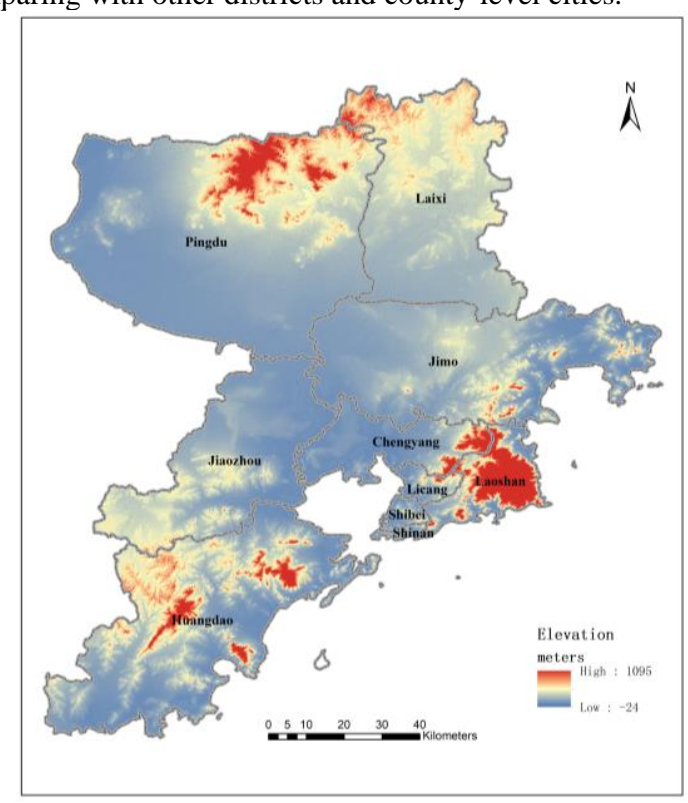

Figure 1. The topography of Qingdao city.

Over last decades, the urban area of Qingdao city expended largely and the urban population increased rapidly. According to the statistics, the population and GDP of Qingdao city increased about $12 \%$ and $142 \%$, respectively.

\section{SATELLITE IMAGES}

The urban land of Qingdao city in 2010, 2015, 2016, 2017, and 2018 were extracted by using satellite images, including Landsat images and China high-resolution satellite images, i.e., GF1 et al. The Landsat images in 2010 with spatial resolution of 30 meters were used to interpreted the urban land area of Qingdao. The images in wide field of view (WFV) mode of

\footnotetext{
${ }^{*}$ Corresponding author
} 
GF1 satellite, with a spatial resolution of 16 meters, in 2015, 2016, 2017, and 2018 were used to update the urban land area in the corresponding years based on the urban land extraction results in 2010. All images were geometrically corrected and projected on to the same coordinate system. Some key parameters of WFV images of GF1 satellite are listed in Table 1.

\begin{tabular}{|c|c|}
\hline Parameters & Values \\
\hline \multirow{4}{*}{ Bands } & Band 1: $0.45 \sim 0.52 \mu \mathrm{m}$ \\
\hline & Band 2: $0.52 \sim 0.59 \mu \mathrm{m}$ \\
\hline & Band 3: $0.63 \sim 0.69 \mu \mathrm{m}$ \\
\hline & Band 4: $0.77 \sim 0.89 \mu \mathrm{m}$ \\
\hline Spatial resolution & $16 \mathrm{~m}$ \\
\hline Swath & $800 \mathrm{~km}$ \\
\hline Revisiting time & 4 days \\
\hline
\end{tabular}

Table 1. Some key parameters of WFV images of GF1 satellite

\section{METHOD}

\subsection{Urban land extraction}

To keep reasonability of spatiotemporal pattern analysis of urban land expansion, we defined the urban land according to satellite images characteristics. The urban land includes the impervious areas in the city built-up areas and some industrial park near the built-up area. The urban land of Qingdao city in 2010, 2015, 2016, 2017, and 2018 were extracted by human interpretation based on Landsat images and high-resolution satellite images according to the same definition.

\subsection{Urban land expansion analysis}

Three aspects, including urban land expansion rate, land cover types and coordination between urban land expansion and urbanization rate were analyzed to reveal the pattern and quality of urban expansion in Qingdao city.

The annual urban land expansion rate is defined as

$$
R=\left(\frac{A_{i}}{A_{0}}\right) / Y,
$$

Where $R=$ urban land expansion rate

$A_{i}=$ the area of urban land in different years

$A_{0}=$ the area of urban land in base year

$Y=$ the number of years between different years

The proportions of different land cover types, including impervious area, cropland, forest, grassland, water and bare land, in urban built-up area and expansion area were calculated to reveal the land structure of urban land.

\subsection{Land cover type and population analysis}

The coordination between urban land expansion and people urbanization was also an important aspect of the urban land expansion quality. The correlation coefficient between urban land area and urbanization rate was used to quantitatively evaluate the matching level between urban land expansion and population increase.

\section{RESULTS}

\subsection{Urban land expansion}

The urban land area of Qingdao city was $1,210.02 \mathrm{~km}^{2}$ in 2010 , and expanded to $1,357.30 \mathrm{~km}^{2}, 1,381.18 \mathrm{~km}^{2}, 1,402.98 \mathrm{~km}^{2}$, and $1,406.33 \mathrm{~km}^{2}$, in $2015,2016,2017$, and 2018 , respectively. The annual urban land expansion rates of $2010-2015$, 20152016, 2016-2017, and 2017-2018 are 2.43\%, 1.76\%, 1.58\%, and
$0.24 \%$, indicating the urban expansion process decreased gradually from 2010 to 2018(Figure 1, Table 2).

As for the different districts and county-level cities in Qingdao city, the urban land area and annual urban land expansion rates are quite different. Figure 1 shows the urban land area of districts and county-level cities in Qingdao from 2010 to 2018. The urban land of three districts, including Jiaozhou, Chengyang, and Huangdao, expended significantly from 2010 to 2018. However, the urban land expansion rates of Shibei and Shinan district are almost zero (Figure 2, Table 3). The districts and county-level cities in Qingdao city can be separated from three groups according to the urban expansion characteristics from 2010 to 2018:

(1) the districts with zero urban land expansion rates include Shibei and Shinan. These two districts are located in the traditional built-up areas of Qingdao city. Most of areas in these two districts have been developed as impervious areas in 2010, and there are almost no other spaces to construct new buildings. Therefore, the urban land expansion rates are zero from 2010 to 2018.

(2) the districts and county-level cities with the urban land expansion area mainly performed from 2010 to 2016, including Laixi, Laoshan, and Licang. The urban land expansion rates are zero in 2017 and 2018.

(3) the districts and county-level cities with the urban land areas keep expanding from 2010 to 2018, including Chengyang, Huangdao, Jimo, Jiaozhou, and Pingdu.

\begin{tabular}{|l|r|r|r|r|r|}
\hline & 2010 & 2015 & 2016 & 2017 & 2018 \\
\hline Chengyang & 226.17 & 238.10 & 239.06 & 241.66 & 242.01 \\
\hline Huangdao & 220.27 & 262.00 & 272.49 & 274.99 & 277.05 \\
\hline Jimo & 188.23 & 219.84 & 220.86 & 226.07 & 226.07 \\
\hline Jiaozhou & 175.78 & 201.55 & 206.97 & 218.11 & 218.84 \\
\hline Laixi & 81.73 & 94.40 & 96.24 & 96.24 & 96.24 \\
\hline Laoshan & 63.72 & 71.98 & 71.98 & 71.98 & 71.98 \\
\hline Licang & 73.64 & 78.97 & 78.97 & 78.97 & 78.97 \\
\hline Pingdu & 88.57 & 98.54 & 102.69 & 103.05 & 103.25 \\
\hline Shibei & 64.39 & 64.39 & 64.39 & 64.39 & 64.39 \\
\hline Shinan & 27.53 & 27.53 & 27.53 & 27.53 & 27.53 \\
\hline Total & 1210.02 & 1357.30 & 1381.18 & 1402.98 & 1406.33 \\
\hline
\end{tabular}

Table 2. Urban land areas from 2010 to 2018 of different districts and county-level cities in Qingdao city.

\begin{tabular}{|l|r|r|r|r|}
\hline & $2010-2015$ & $2015-2016$ & $2016-2017$ & $2017-2018$ \\
\hline Chengyang & $1.05 \%$ & $0.40 \%$ & $1.09 \%$ & $0.15 \%$ \\
\hline Huangdao & $3.79 \%$ & $4.00 \%$ & $0.92 \%$ & $0.75 \%$ \\
\hline Jimo & $3.36 \%$ & $0.46 \%$ & $2.36 \%$ & $0.00 \%$ \\
\hline Jiaozhou & $2.93 \%$ & $2.69 \%$ & $5.38 \%$ & $0.34 \%$ \\
\hline Laixi & $3.10 \%$ & $1.95 \%$ & $0.00 \%$ & $0.00 \%$ \\
\hline Laoshan & $2.59 \%$ & $0.00 \%$ & $0.00 \%$ & $0.00 \%$ \\
\hline Licang & $1.45 \%$ & $0.00 \%$ & $0.00 \%$ & $0.00 \%$ \\
\hline Pingdu & $2.25 \%$ & $4.21 \%$ & $0.35 \%$ & $0.20 \%$ \\
\hline Shibei & $0.00 \%$ & $0.00 \%$ & $0.00 \%$ & $0.00 \%$ \\
\hline Shinan & $0.00 \%$ & $0.00 \%$ & $0.00 \%$ & $0.00 \%$ \\
\hline Average & $2.43 \%$ & $1.76 \%$ & $1.58 \%$ & $0.24 \%$ \\
\hline
\end{tabular}

Table 3. The annual urban land expansion rates of differentdistricts and county-level cities in Qingdao city. 


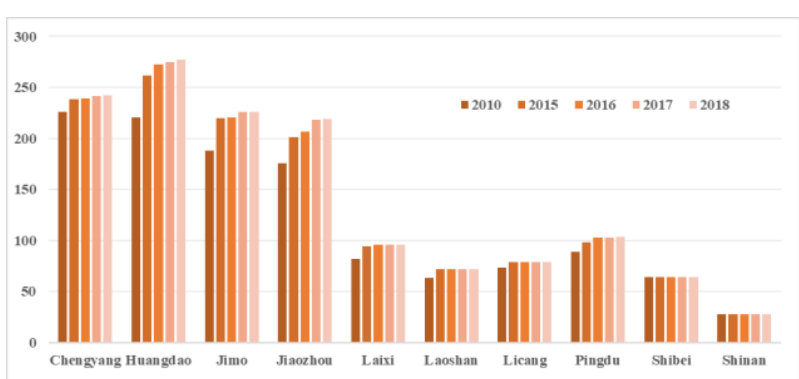

Figure 1. Urban land area of different districts and county-level cities in Qingdao from 2010 to 2018.

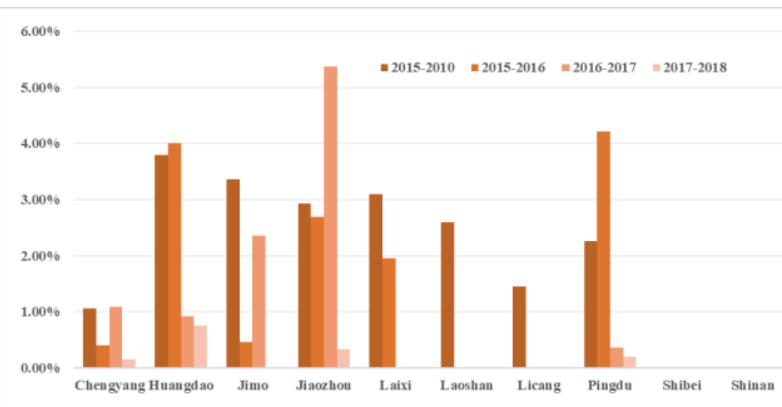

Figure 2. Annual urban land expansion rates of different districts and county-level cities in Qingdao from 2010 to 2018.

\subsection{Land cover types in built-up areas}

To some extent, the land cover types in the built-up area indicates the land use structure, which determines the urban function layout. Furthermore, the land use structure is highly related to the habitability for a city. In this section, we use the land cover types with the spatial resolution of 30 meters to analyze the land cover structures in the built-up area. The land cover results are interpreted based on Landsat images in 2018, with six types including impervious area, cropland, forest land, grassland, water, and bare land.

There were $36.8 \%$ and $31.5 \%$ croplands in Laixi and Jimo. There were more forest and grassland in Laoshan, revealing that the land cover types in urban built-up area were relatively balance (Figure3). Table 4 has shown the area proportions of different land cover types for different districts and county-level cities in Qingdao in 2010. It can be seen that over 95\% land cover types were impervious area in the build-up areas, e.g. Shibei and Shinan district. However, there were more forest and water land in the suburban counties.

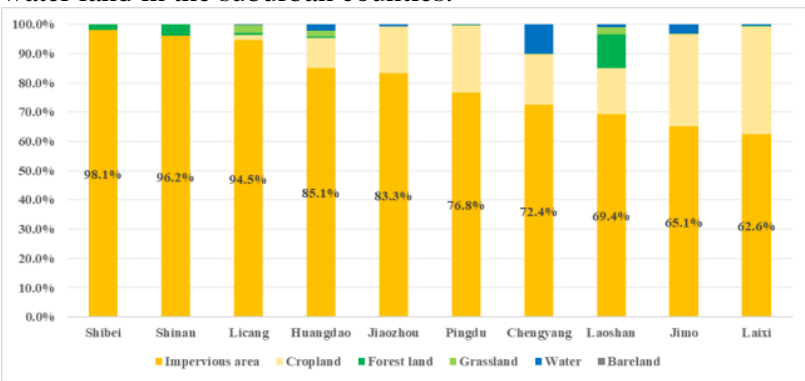

Figure 3. The area proportions of different land cover types in urban built-up area in 2010.

\begin{tabular}{|l|r|r|r|r|r|r|}
\hline & IM & CP & FL & GL & WA & BL \\
\hline Shibei & 98.1 & 0.0 & 1.9 & 0.0 & 0.0 & 0.0 \\
\hline Shinan & 96.2 & 0.0 & 3.8 & 0.0 & 0.0 & 0.0 \\
\hline Licang & 94.5 & 1.8 & 0.9 & 2.7 & 0.1 & 0.0 \\
\hline Huangdao & 85.1 & 10.3 & 0.6 & 1.8 & 2.2 & 0.1 \\
\hline
\end{tabular}

\begin{tabular}{|l|r|r|r|r|r|r|}
\hline Jiaozhou & 83.3 & 15.9 & 0.0 & 0.0 & 0.8 & 0.0 \\
\hline Pingdu & 76.8 & 22.7 & 0.1 & 0.2 & 0.3 & 0.0 \\
\hline Chengyang & 72.4 & 17.2 & 0.1 & 0.3 & 10.0 & 0.0 \\
\hline Laoshan & 69.4 & 15.7 & 11.6 & 2.3 & 1.0 & 0.0 \\
\hline Jimo & 65.1 & 31.5 & 0.0 & 0.3 & 3.2 & 0.0 \\
\hline Laixi & 62.6 & 36.8 & 0.1 & 0.0 & 0.6 & 0.0 \\
\hline
\end{tabular}

Table 4. The area proportions of different land cover types of different districts and county-level cities in Qingdao in 2010

(IM-Impervious area,CP-Cropland, FL-Forest land,GLGrassland, WA-Water, BL-Bare land) .

\begin{tabular}{|l|r|r|r|r|r|r|}
\hline & \multicolumn{1}{l|}{ IM } & \multicolumn{1}{l|}{ CP } & \multicolumn{1}{l|}{ FL } & \multicolumn{1}{l|}{ GL } & \multicolumn{1}{l|}{ WA } & \multicolumn{1}{l|}{ BL } \\
\hline Laoshan & 90.2 & 4.4 & 1.0 & 3.8 & 0.6 & 0.0 \\
\hline Jiaozhou & 69.8 & 25.7 & 0.0 & 0.0 & 3.9 & 0.5 \\
\hline Licang & 62.3 & 6.6 & 13.9 & 16.3 & 0.9 & 0.0 \\
\hline Pingdu & 51.4 & 45.6 & 0.0 & 0.0 & 0.8 & 2.2 \\
\hline Chengyang & 51.2 & 27.3 & 0.0 & 5.3 & 16.2 & 0.0 \\
\hline Huangdao & 49.8 & 44.2 & 0.4 & 1.0 & 4.6 & 0.0 \\
\hline Jimo & 44.4 & 54.5 & 0.0 & 0.1 & 1.0 & 0.0 \\
\hline Laixi & 42.5 & 57.4 & 0.0 & 0.1 & 0.0 & 0.0 \\
\hline
\end{tabular}

Table 5. The area proportions $(\%)$ of different land cover types for the expansion areas in different districts and county-level cities(IM-Impervious area,CP-Cropland, FL-Forest land,GLGrassland, WA-Water, BL-Bare land).

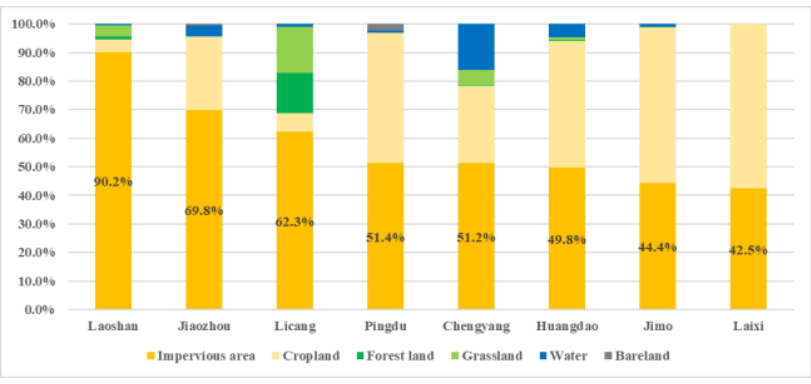

Figure 4. The area proportions of different land cover types for the expansion areas.

As to the urban expansion area, most of the land cover types were impervious area, except Huangdao, Jimo, and Laixi. There were over $50 \%$ croplands in urban expansion areas in these three districts. Furthermore, there are some forest land and grasslands in urban expansion areas in Licang.

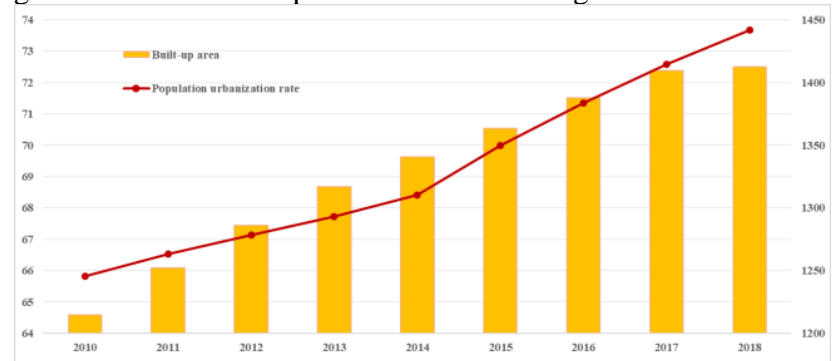

Figure 5. Variations of urban land areas and people urbanization rate from 2010 to 2018. 


\subsection{Coordination between urban land expansion and people urbanization}

It is important of urban land expansion that there are more and more people from rural to urban area and more urban land is needed for the new comers. Thus, the coordination between urban land expansion and people urbanization is very important to evaluate the quality of urban land expansion for a city.

According to the statistics, the urbanization rate of Qingdao city increased about $7.8 \%$, while the urban land area expanded about $16.3 \%$ from 2010 to 2018 . Figure 5 shows the changes of the urbanization rate and urban land expansion area. It can be seen that they are highly correlated, and the correlation coefficient between urban land area and urbanization rate is 0.95 (Figure 6).

It is also obvious that the urbanization rate goes up in almost a straight style from 2014 to 2018. However, the urban land expansion rate is very small from 2017 to 2018. Therefore, it has a potential of imbalance between urbanization rate and urban land area in the future.

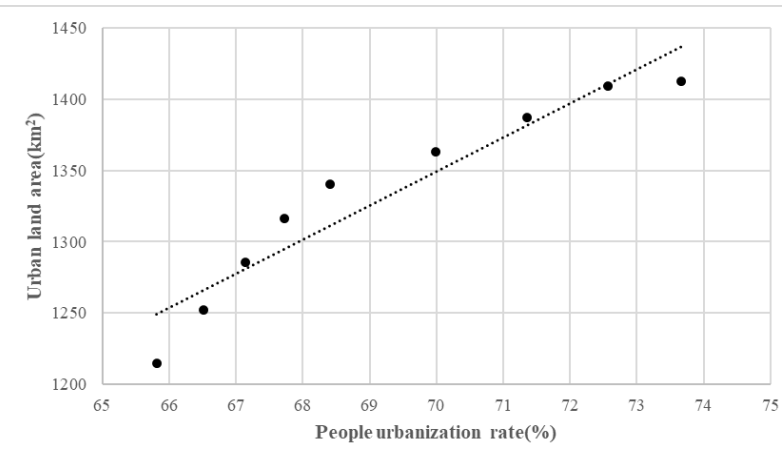

Figure 6. Relationship between the urban land area and urbanization rate.

\section{CONCLUSIONS AND DISCUSSIONS}

In this paper, the urban land areas of Qingdao city in 2010, 2015, 2016, 2017, and 2018 were extracted from satellite images. The variations of urban land expansion and annual urban land expansion rates from 2010 to 2018 were calculated in different districts and county-level cities. Furthermore, to reveal the quality of urban land expansion, the land cover types of the urban expansion area and urbanization rate were also analyzed. It has shown that most of the build-up areas are impervious land. Also, the urban land expansion areas and the urbanization rate has high positive correlation, with a correlation coefficient of 0.95 .

It should be noted that the urban land areas were extracted by satellite images with the spatial resolution of 16 meters. The results can reveal the urban land expansion patterns in moderate scale. It is limited to study urban expansion in fine scale, especially in the regions of urban-rural fringe. Fortunately, with the launches of high-resolution satellites in China, e.g., ZY3, GF2 et al., the coverage ability of satellite images with the resolution of 2 meters greatly strengthens in recent years. It provides the possibility of revealing the urban land expansion laws in much finer scales.

\section{ACKNOWLEDGEMENTS}

This work is supported by the National Key Research and Development Program of China (NO.2018XXXXXXXX0N).

\section{REFERENCES}

Chai, B., Li, P., 2018. Annual Urban Expansion Extraction and Spatio-Temporal Analysis Using Landsat Time Series Data: A Case Study of Tianjin, China. IEEE Journal of Selected Topics in Applied Earth Observations and Remote Sensing, 11(8), 2644-2656.

Li D, Li, X. 2015. An overview on data mining of nighttime light remote sensing. Acta Geodaetica Et Cartographica Sinica, 44(6), 591-601.

Wang H., Ning. X., Zhang H., Liu Y. 2019. Urban Expansion Analysis of China's Prefecture Level City from 2000 to 2016 using High-Precision Urban Boundary. 2019 IEEE International Geoscience and Remote Sensing Symposium,7514-7517.

Gao, F., de Colstoun E. B., et al., 2012. Mapping impervious surface expansion using medium-resolution satellite image time series: a case study in the Yangtze River Delta, China. International Journal of Remote Sensing, 33 (24): 7609-7628.

Wang, L., Li, C., et al., 2012. China's urban expansion from 1990 to 2010 determined with satellite remote sensing. Chinese Science Bulletin, 57 (22): 2802-2812.

Yu B, Wang C, Gong W, Chen Z, Shi K, Wu B, Hong Y C, Li Q and Wu J. 2021. Nighttime light remote sensing and urban studies: Data, methods, applications, and prospects. National Remote Sensing Bulletin, 25 (1) : 342364 